Chronic Obstructive Pulmonary Diseases: Journal of the COPD Foundation

\author{
A Statement of the COPD Foundation
}

\title{
Introducing the New COPD Pocket Consultant Guide App: Can A Digital Approach Improve Care? A Statement of the COPD Foundation
}

Byron Thomashow, MD ${ }^{1}$ James D. Crapo, $\mathrm{MD}^{2}$ M. Bradley Drummond, MD ${ }^{3}$ MeiLan K. Han, MD ${ }^{4}$ Ravi Kalhan, $\mathrm{MD}^{5}$ Elisha Malanga, $\mathrm{BS}^{6}$ Vinny Malanga, BS, $\mathrm{MCP}^{6}$ David M. Mannino, $\mathrm{MD}^{7}$

Stephen Rennard, $\mathrm{MD}^{8}$ Frank C. Sciurba, $\mathrm{MD}^{9}$ Kristen S. Willard, $\mathrm{MS}^{6}$ Robert Wise, $\mathrm{MD}^{10}$ Barbara Yawn, $\mathrm{MD}^{6}$

\begin{abstract}
The COPD Foundation has tried to address gaps in chronic obstructive pulmonary disease (COPD) care by providing COPD Pocket Consultant Guide cards to U.S. health care providers. Since launching the card in 2007, there have been numerous updates and more than 800,000 of these cards have been distributed at no charge to health care professionals. The most recent versions have concentrated on presenting an algorithm for COPD management based on 7 severity domains: spirometry, symptoms, exacerbations, oxygen requirements, the presence of chronic bronchitis or emphysema and comorbidities. To increase the usability and reach of this tool, the COPD Pocket Consultant Guide is now available as an app for iOS and Android. This updated version of the app includes new COPD and asthma/COPD overlap flow charts; an interactive therapy chart that takes into account modified Medical Research Council (mMRC), COPD Assessment Test (CAT), and spirometry scores; anxiety and depression screeners; up-to-date medication charts in both brand and generic formats; a checklist to aid in determining when a patient should be referred to a pulmonologist and more. Potential use of the COPD Pocket Consultant Guide app in clinical care is discussed.
\end{abstract}

Abbreviations: chronic obstructive pulmonary disease, COPD; modified Medical Research Council dyspnea scale, mMRC; COPD Assessment Test, CAT; COPD Pocket Consultant Guide, PCG; Global initiative for chronic Obstructive Lung Disease, GOLD; spirometry grade, SG; COPD Genetic Epidemiology, COPDGene ${ }^{\oplus}$; computed tomography, CT; forced expiratory volume in 1 second, FEV $\mathbf{1}$; asthma/ COPD overlap, ACO; long-acting muscarinic antagonist, LAMA; long-acting beta2-agonist, LABA; inhaled corticosteroid, ICS; Food and Drug Administration, FDA; Dyspnoea, Eosinopenia, Consolidation, Acidemia and Atrial Fibrillation, DECAF

Funding Support: None

Date of Acceptance: April 4, 2018

Citation: Thomashow B, Crapo JD, Drummond MB, et al. Introducing the new COPD Pocket Consultant Guide app: can a digital approach improve care? A statement of the COPD Foundation. Chronic Obstr Pulm Dis. 2019;6(3):210-220. doi: https://doi.org/10.15326/ jcopdf.6.3.2018.0167

1 Division of Pulmonary, Allergy, and Critical Care Medicine, Columbia University, New York

2 Division of Pulmonary, Critical Care and Sleep Medicine, National Jewish Health, Denver, Colorado

3 Division of Pulmonary Diseases and Critical Medicine, Department of Medicine, University of North Carolina, Chapel Hill
4 Division of Pulmonary and Critical Care Medicine, Department of Internal Medicine, University of Michigan Health System, Ann Arbor

5 Asthma and COPD Program, Northwestern University Feinberg School of Medicine, Chicago, Illinois

6 COPD Foundation, Washington, D.C. 
7 GlaxoSmithKline, Philadelphia, Pennsylvania and Department of Preventative Medicine and Environmental Health University of Kentucky, College of Public Health, Lexington

8 Early Clinical Development, IMED Biotech Unit, AstraZeneca, Cambridge, United Kingdom and Department of Medicine, University of Nebraska Medical Center, Omaha

9 Division of Pulmonary Allergy and Critical Care Medicine, University of Pittsburgh, Pittsburgh, Pennsylvania

10 Pulmonary and Critical Care, Department of Medicine, Johns Hopkins University School of Medicine, Baltimore, Maryland

\section{Address correspondence to:}

Byron Thomashow, MD

Email: bmt1@cumc.columbia.edu

Phone: (212)305-5261

\section{Keywords:}

Pocket Consultant Guide; app; COPD; chronic obstructive pulmonary disease; management; maintenance; medication; anxiety; depression; exacerbations; acute exacerbation of COPD; AECOPD

\section{Introduction}

In primary care as well as pulmonary practices, chronic obstructive pulmonary disease (COPD) is a common problem for patients. More than 16 million Americans have been diagnosed with COPD. COPD is now the fourth leading cause of death in the United States and a leading cause of disability. ${ }^{1,2}$

The cost of caring for COPD in the United States exceeds 50 billion dollars a year. ${ }^{3}$ There are a number of excellent COPD guidelines or strategy documents but evidence suggests that COPD care remains suboptimal for many patients, the majority of whom are not treated according to guideline recommendations. ${ }^{4}$ The COPD Foundation has tried to address these gaps in care by providing COPD Pocket Consultant Guide (PCG) cards. Since launching the card in 2007, there have been numerous updates and more than 800,000 of these cards have been distributed to health care professionals at no charge.

The COPD pocket guide is available as a tri-fold card that provides a simplified approach to COPD care. Initial card versions followed the Global initiative for chronic Obstructive Lung Disease (GOLD) ${ }^{5}$ recommended approach. More recent versions have concentrated on presenting an algorithm for COPD management based on 7 severity domains: spirometry, symptoms, exacerbations, oxygen requirements, the presence of chronic bronchitis or emphysema and comorbidities. The cards are available with both brand and generic medication names. Two prior manuscripts have described these consultant cards in detail. ${ }^{6,7}$

While written materials are useful for reference and education, they provide less point of care guidance and support for management during actual visits and may become outdated quickly as new therapies are approved. Therefore, an interactive app has been developed to enhance the usability of the COPD PCG within the direct care setting. The aim of this presentation is to review the content of the app and its potential use in clinical care (Figure 1).

\section{App Description and Contents}

The COPD PCG app is now available for iOS and Android and can be found in both the Apple Store and on Google Play. As shown in Figure 1, the PCG home page, which contains the top-level menu for the app, allows for quick and tailored access to content most likely to be of immediate value to a provider. These content areas are designed to both guide care during a visit and to provide access to material that can be difficult to find.

\section{Model}

Before homing in on medical treatment, it is important to put the patient's COPD in context of their unique disease. To facilitate that, the "Model" section describes the 7 severity domains that have become a central feature of the COPD Foundation approach (see Figure 2). It is worth stressing that the spirometry approach adopted by the Foundation differs from some of the other commonly used spirometry grades. The Foundation approach uses 5 grades, including normal, spirometry grade 0 (SG-O) and a category of undefined with restricted lung function but without obstruction, spirometry grade U (SG-U). These are included because evidence from several large studies, including the COPD Genetic Epidemiology $\left(\right.$ COPDGene $\left.^{\circledR}\right)$ study, has documented that computed tomography (CT) scans in patients with both SG-0 and SG-U often contain significant abnormalities including emphysematous and airway abnormalities. The presence of normal or restricted spirometry does not rule out emphysema, chronic bronchitis, asthma, or 


\section{Figure 1. The COPD Pocket Consultant Guide Main Menu}

\section{. \\ COPD POCKET CONSULTANT GUIDE}

Begin with CAT or mMRC to start the app's interactive function.

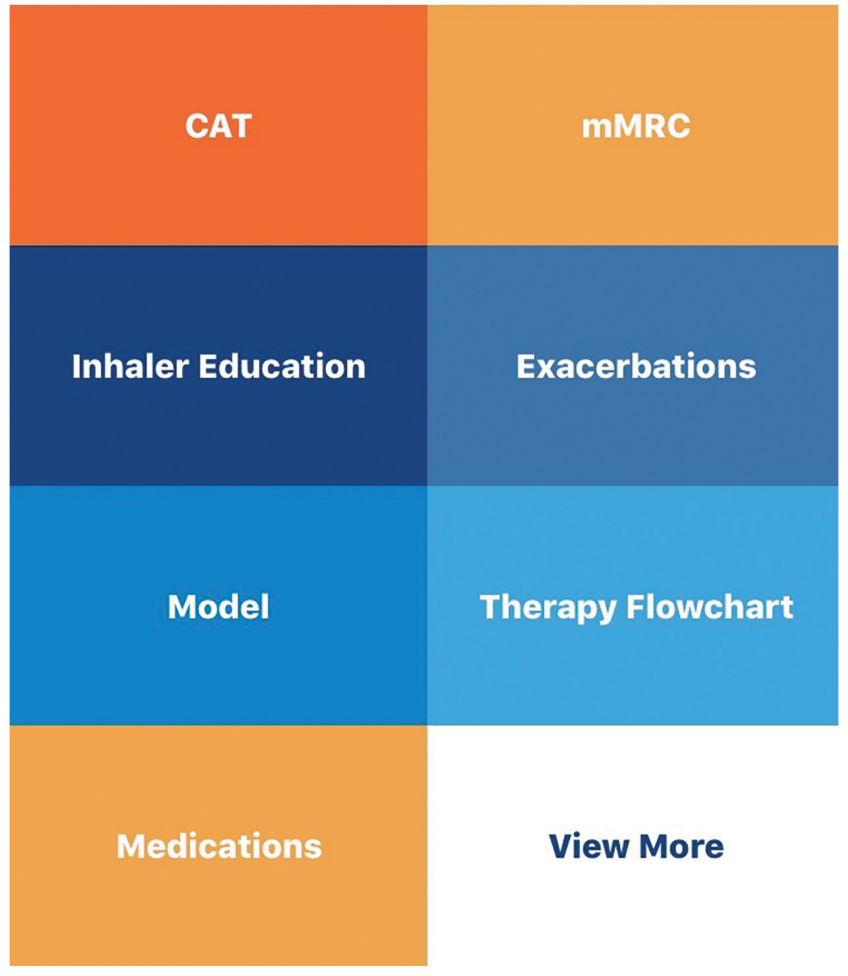

$\mathrm{CAT}=\mathrm{COPD}$ Assessment Test mMRC=modified Medical Research Council

the risk of developing either exacerbations or COPD.

In addition, the Foundation system highlights the potential importance of a forced expiratory volume in 1 second $\left(F E V_{1}\right)<60 \%$ predicted rather than the cut off of $\mathrm{FEV}_{1}<50 \%$ predicted as highlighted in GOLD. ${ }^{5}$ The American College of Physicians, American College of Chest Physicians, American Thoracic Society, and European Respiratory Society Consensus Statement recommendations identified high levels of evidence supporting using $\mathrm{FEV}_{1}<60 \%$ predicted as a cut-offpoint. ${ }^{8}$ In COPD patients with $\mathrm{FEV}_{1}<60 \%$ predicted, evidence is clear that available medications

\section{Figure 2. Seven COPD Severity Domains}

\author{
Assess Severity Domains \\ Each domain may have therapeutic implications. \\ Spirometry Grades: \\ SG 0 Normal spirometry does not rule out emphysema, chronic bronchitis, asthma, or risk \\ of developing either exacerbations or COPD. \\ SG 1 Mild: Post bronchodilator $\mathrm{FEV}_{1} / \mathrm{FVC}$ ratio $<0.7, \mathrm{FEV}_{1} \geq 60 \%$ predicted. \\ SG 2 Moderate: Post bronchodilator $\mathrm{FEV}_{1} / \mathrm{FVC}$ ratio $<0.7,30 \% \leq \mathrm{FEV}_{1}<60 \%$ predicted. \\ SG 3 Severe: Post bronchodilator $\mathrm{FEV}_{1} / \mathrm{FVC}$ ratio $<0.7, \mathrm{FEV}_{1}<30 \%$ predicted. \\ SG U Undefined: $\mathrm{FEV} / \mathrm{FVC}$ ratio $\geq 0.7, \mathrm{FEV}_{1}<80 \%$ predicted. This is consistent with restric- \\ tion, muscle weakness, and other pathologies.

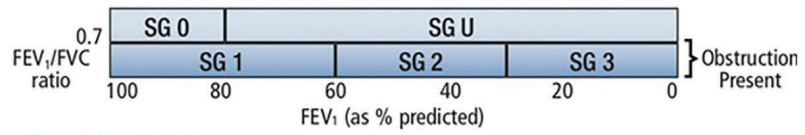 \\ Regular Symptoms: dyspnea at rest or exertion, cough, sputum. Use COPD Assessment \\ Test (CAT) or mMRC Breathlessness Scale to follow course of disease. \\ Exacerbations: two or more in the past year, especially if $\mathrm{FEV}_{1}<50 \%$ predicted suggests \\ high risk. \\ Oxygenation: severe hypoxemia: resting $02 \mathrm{sat} \leq 88 \%$ or arterial $\mathrm{p} 02<55 \mathrm{mmHg}$ \\ episodic hypoxemia: exercise or nocturnal desaturation. \\ Emphysema: reduced density on CT scan, can be localized, abnormal high lung volumes, \\ abnormal low diffusion capacity. \\ Chronic bronchitis: cough, sputum most days for at least 3 months in at least 2 years. \\ Comorbidities: defining and treating comorbid conditions, particularly cardiovascular, anxiety \\ and depression, are critical components of COPD care.
}

$\mathrm{SG}=$ spirometry grades; $\mathrm{COPD}=$ chronic obstructive pulmonary disease; $\mathrm{FEV}_{1}=$ forced expiratory volume in 1 second; $\mathrm{FVC}=$ forced vital capacity; $\mathrm{CAT}=\mathrm{COPD}$ Assessment Test; mMRC=modified Medical Research Council; $\mathrm{CT}=$ computed tomography; $\mathrm{O}_{2}=$ oxygen level; $\mathrm{pO}_{2}=$ partial pressure of oxygen

are effective and indicated. In those with $\mathrm{FEV}_{1}>60 \%$, the evidence is less clear regarding the impact of available medications in symptom and exacerbation risk control.

\section{Flowchart}

From this home page, many clinicians may choose to begin using the app with the "Flowchart" section that gives an overview of medical therapy for both COPD and asthma/COPD overlap (ACO) (Figures 3 and 4). The flowchart has been adjusted to address evidence from several recently published studies. Multiple studies have demonstrated that combinations of a long-acting muscarinic antagonist agent (LAMA) and long-acting beta2-agonist agent (LABA) are more effective in addressing significant symptoms and functional status limitations than either agent alone with no evidence of increased side effects. The FLAME study compared indacaterol/glycopyrrenium (dual bronchodilator therapy) with salmeterol/ fluticasone (single bronchodilator plus inhaled corticosteroid [ICS]) in 3200 patients and found that the dual bronchodilator therapy group had $11 \%$ fewer 
Figure 3. COPD Flowchart

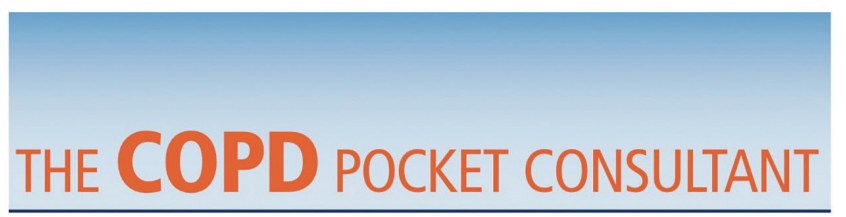

COPD Foundation Guide

for Management of COPD

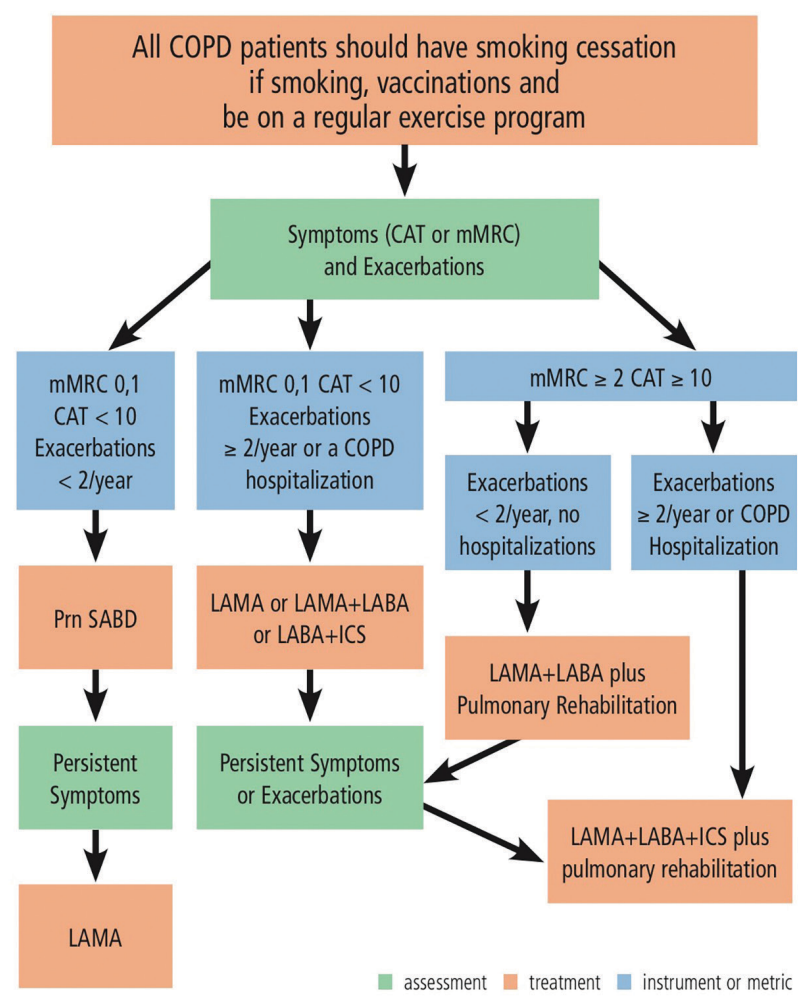

$\mathrm{CAT}=\mathrm{COPD}$ Assessment Test; $\mathrm{mMRC}=$ Dyspnea assessment test; $\mathrm{SABD}=$ short-acting bronchodilator; LAMA=long-acting muscarinic antagonists; LABA=long-acting beta2-agonist; ICS=inhaled corticosteroid

exacerbations with a lower incidence of pneumonia. ${ }^{9}$

More recently, several studies have looked at the potential role for "triple" therapy LAMA/LABA/ICSdual bronchodilator plus ICS - use in care of patients with more severe COPD. The TRIBUTE study enrolled 1500 individuals and compared beclomethasone/ formoterol/glycopyrrenium (triple therapy) versus indacterol/glycopyrrenium (dual bronchodilator therapy) and found moderate-to-severe exacerbations were 0.5 per patient per year in the triple group compared to 0.59 in the LAMA/LABA group with no difference in adverse reactions. ${ }^{10}$ In the IMPACT study of over 10,000 patients, those on fluticasone/ umcelidinum/vilanterol (triple therapy) had a 15\%

\section{Figure 4. Asthma COPD Overlap Flowchart}

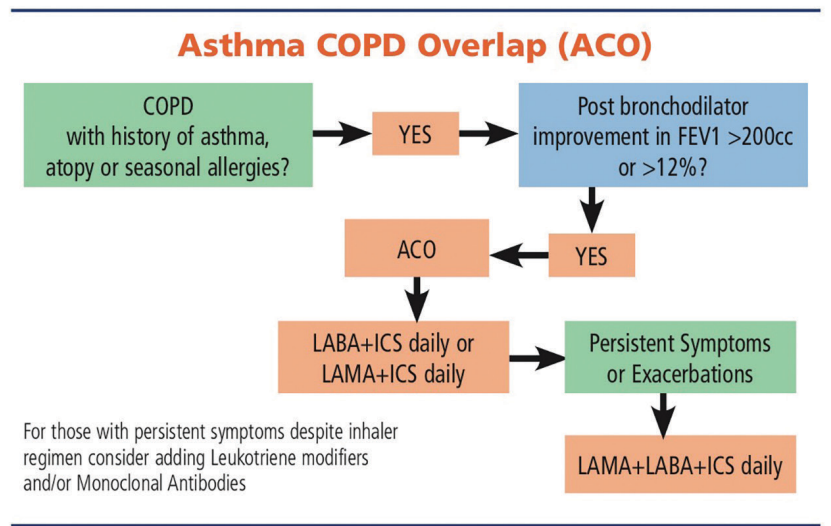

National Quit Smoking Line: 1-800-Quit NOW (784-8669)

COPD Foundation Information Line: 1-866-316-COPD (2673)

COPD 360: http://copd360social.org

Inhaler instruction videos available: https://copdf.co/videos

Free App: search "COPD Pocket Consultant Guide" in App store or Google Play.

The COPD POCKET CONSULTANT is provided by the COPD Foundation as an educational resource only and should not be considered as offering medical advice. This information should not be used as a substitute for the exercise or receipt of a physician's independent professional judgement in providing advice, diagnosis or the exercise or receipt of a physician's independent professional judgement in providing advice, diagnosis or
treatment for any medical or health condition.
Updated August 2018

\section{ACOPDFoundation}

www.copdfoundation.org

$\mathrm{FEV}_{1}=$ forced expiratory volume in 1 second; LABA=long-acting beta2-agonist; LAMA=long-acting muscarinic antagonist; ICS-inhaled corticosteroid

reduction in moderate-to-severe exacerbations compared to the fluticasone/vilanterol (ICS plus single bronchodilator therapy) group and a $28 \%$ reduction compared to the umcelidinium/vilanterol (dual bronchodilator therapy) group. ${ }^{11}$

These results suggest that there may well be a subset of patients with more severe COPD and frequent exacerbations or COPD hospitalizations who could benefit from advancing more rapidly to triple therapy rather than the more classic approach of advancing to triple therapy if symptoms and exacerbations are not adequately controlled with dual bronchodilator therapy. The 2018 flowchart and app have been adjusted to account for the newer evidence.

There has been considerable interest in the potential role of eosinophils to identify those individuals who may benefit from ICS. ${ }^{12}$ Available data suggest that the higher the eosinophil count the more likely ICS has a role, the lower the eosinophil count the less likely ICS is needed. Unfortunately, in clinical practice the role of eosinophil monitoring and an exact threshold to use for eosinophil directed care remains unclear. Evidence suggests that there is individual variability 
of eosinophil counts over time, and there appears to be an interaction between eosinophil levels and smoking status. In addition, the National Health and Nutrition Examination Survey data report that $70.7 \%$ of participants with COPD and $65.5 \%$ of those with normal lung function had eosinophil levels $>2 \%$, with similar distributions of eosinophil percentages and count. ${ }^{13}$ While eosinophil levels may ultimately help with decisions, at this point more data is needed to understand how best to use this information in individual patients. Another area that has received considerable attention relates to the concept of stepping down from triple therapy (dual bronchodilator plus ICS) to LAMA/LABA. Two recent studies - the WISDOM study ${ }^{14}$ and the SUNSET study $^{15}$ - suggest that many patients could safely have their therapy adjusted by withdrawal of the ICS. Of note in the SUNSET study, those with the highest eosinophil counts (levels over 300) were at greater risk of exacerbations with the therapy step down. In the "Model" section and in the "Special Consideration Section," the Foundation app suggests that for those well controlled (0-1 exacerbation in the past year and no COPD hospitalizations) on triple therapy, consideration can be given to stepping down to dual bronchodilator therapy (LAMA+LABA) with careful follow up. This consideration is especially important in those with potential ICS-related comorbidities such as a history of recurrent pneumonias, osteoporosis or cataracts. Conversely, the presence of significant eosinophilia may help select those "exacerbators" who could benefit from continued use of ICS.

Other bullet points raise the option of adding therapies to those who continue to exacerbate despite use of triple therapy inhaler regimen such as the addition of phosphodiesterase type 4 inhibitor roflumilast if the patient has chronic bronchitis, ${ }^{16}$ and/ or a macrolide as an immune modulator in patients who are not current smokers. ${ }^{17}$

The Flowchart section also includes a flowchart for addressing ACO (Figure 4). This is a complicated issue since it has not been well defined. ${ }^{18}$ Both asthma and COPD are very common disorders and therefore it is not surprising that they occur together. In addition, it is well recognized that in chronic asthma, airway remodeling can lead to a component of fixed obstruction that is similar to that seen in COPD. The app suggests that in those with a fixed obstruction component who have a history of asthma, atopy or seasonal allergies and a significant bronchodilator response in post bronchodilator spirometry, ACO is a consideration. In that setting, appropriate therapy will include an ICS linked to either a LABA or a LAMA or both as part of the initial treatment regimen. For those more symptomatic, especially with high eosinophil counts, an argument could be made to initiate therapy with a triple regimen and then consider adjusting once adequate control achieved. In those with suspected ACO who are on a maximal inhaler regimen but continue to struggle, adding a leukotriene modifier and/ or a monoclonal antibody should be a consideration.

\section{Medications}

For quick reference, the "Medications" section lists Food and Drug Administration (FDA)-approved medications with dosing information (see Figures e 1 and $e 2$ in the online supplement). The user can use a toggle switch to view both brand and generic names of drugs. One of the advantages of the new app is that the COPD Foundation can list new drugs as soon as they receive FDA approval-an advantage not possible with printed guidelines.

\section{Exacerbations}

The "Exacerbations" section provides definitions and potential therapy options. Treatment of acute exacerbations centers around maximizing bronchodilator use, adding systemic steroids and when appropriate a course of antibiotics. Evidence strongly suggests that when steroids are indicated, a short course of systemic steroids, as short as 5 days, is as beneficial as longer courses while minimizing side effects.

\section{Inhaler Education}

The "Inhaler Education" section provides videos of all available inhaler devices in one place. The inhaler demonstration videos may be utilized by nursing staff, clinicians, respiratory therapists and others during a visit or hospitalization to introduce or review inhaler technique before observing patients preforming those techniques. Several practical, clinical studies have shown that it is not sufficient to simply show patients how to use a device. ${ }^{19}$ Observing the patient using a "teach back" approach is critical to assuring the patient can actually preform adequate inhaler use. $^{20}$ The number of videos available through the app emphasizes the increasing complexity of inhaler 
technique training as the number and variations of available devices grows. This app may also find a use within the hospital setting where increased pressure on reducing preventable COPD 30-day readmissions has focused attention on patient participation including making sure that inhaler technique has been perfected prior to discharge.

\section{New Interactive Operations}

The component of the new app which has generated the most interest is the interactive program initiated by tapping either the COPD Assessment Test (CAT) or modified Medical Research Council (mMRC) box. (Watch a demo of the app here at https://www.youtube. com/watch?v=JwggDVf3TGs.)

Once the CAT (Figure 5) or mMRC (Figure 6) has been completed, a score is generated and an exacerbation screen appears (see Figure e3 in online supplement) asking if the patient has had 2 or more exacerbations a year or 1 or more COPD hospitalizations. Completion of that screen leads to a spirometry screen (see Figure e 4 in online supplement).

If spirometry is not available, the user is directed back to the COPD Flowchart to use symptoms and exacerbations to address therapy options. If spirometry is available, the combined results of symptoms, exacerbation, and spirometry screens leads to an interactive chart where potential therapeutic options are highlighted (see Figure 7). Therapy is guided by assessment of severity domains. Each domain requires separate treatment consideration. Risk and benefits always need to be evaluated in every case. A small orange and blue pinwheel icon represents potential first line therapy. An orange and red circle represents second line choices. The COPD Flowchart can further help define therapy options .

\section{In the Interactive Therapy Chart}

- If spirometry results suggest SG-O or SG-U, then none of the areas on the chart is highlighted; however, a bullet point stresses that if symptomatic with SG-0 or SG-U, further evaluation is indicated to better define etiology and any therapeutic options. Likewise, if significant shortness of breath is present with SG-1, mild COPD, a bullet point stresses that the user should consider potential contributing factors including cardiac and deconditioning.

\section{Figure 5. The COPD Assessment Test}

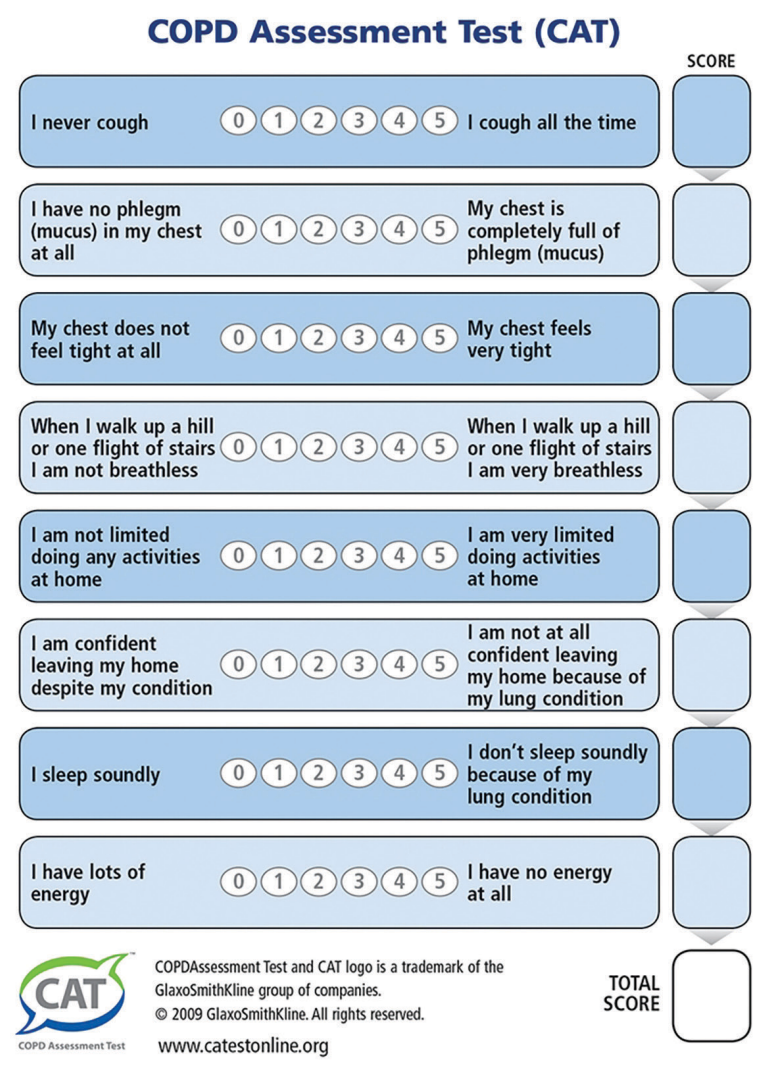

\section{Figure 6. The Modified Medical Research Council Dyspnea Scale}

\footnotetext{
$\overline{\text { mMRC Breathlessness Scale }}$

\begin{tabular}{|c|c|}
\hline Grade & Description of Breathlessness \\
\hline 0 & I only get breathless with strenuous exercise \\
\hline 1 & I get short of breath when hurrying on level ground or walking up a slight hill \\
\hline 2 & $\begin{array}{l}\text { On level ground, I walk slower than people of the same age because of } \\
\text { breathlessness, or have to stop for breath when walking at my own pace }\end{array}$ \\
\hline 3 & $\begin{array}{l}\text { I stop for breath after walking about } 100 \text { yards or after a few minutes on } \\
\text { level ground }\end{array}$ \\
\hline 4 & I am too breathless to leave the house or I am breathless when dressing \\
\hline
\end{tabular}

mMRC=modified Medical Research Council

- The Therapy Chart and the Flowchart both stress the importance of pulmonary rehabilitation and regular exercise programs.

- If either or both of the exacerbation questions are checked off, then the exacerbation row is highlighted. Which exacerbation therapy option the
} 


\section{Figure 7. Interactive Therapy Chart}

Back OOPD Diagnosis
Tap any icon in the Therapy Chart
for additional information
Based on the results you entered for symptoms, spirometry and
exacerbation history, some severity domains will be highlighted. These
severity domains should be considered for treatment options.

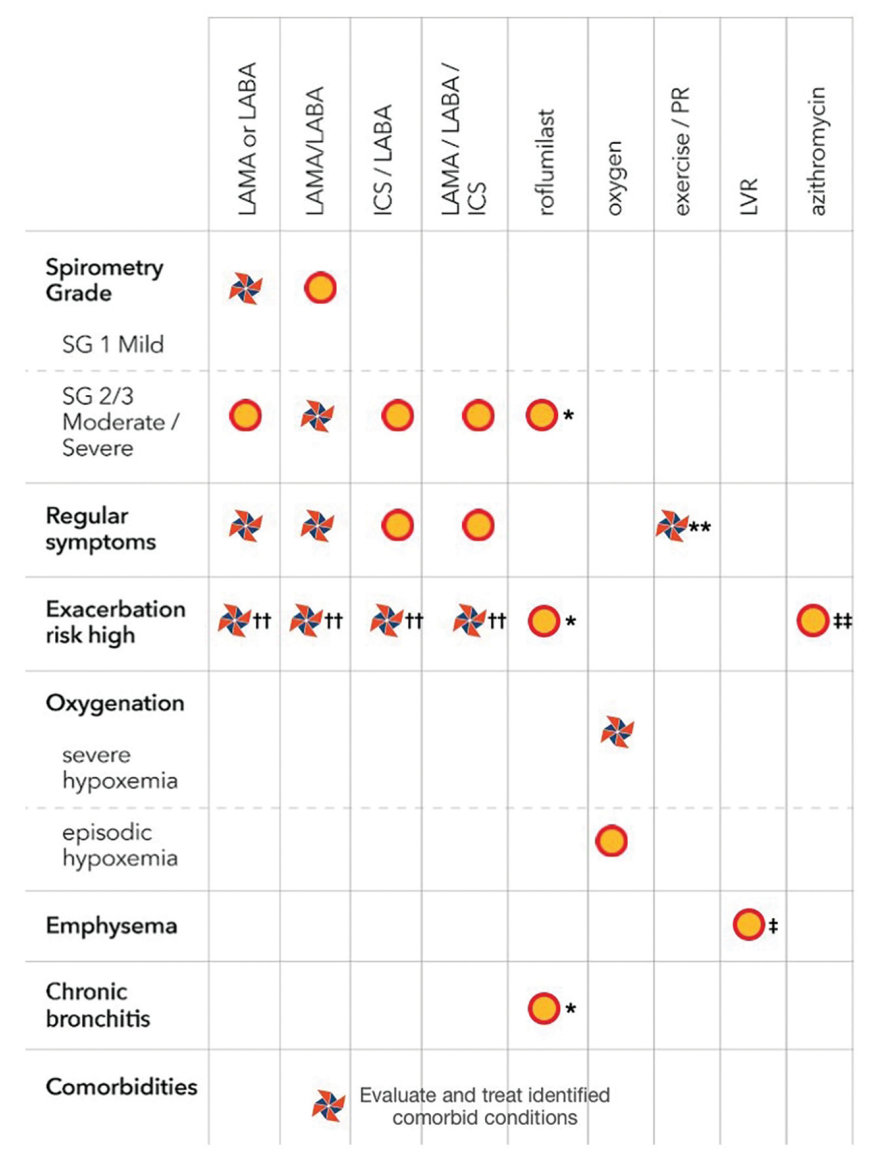

$\mathrm{SG}=$ spirometry grade; LAMA=long-acting muscarinic antagonists; LABA=long-acting beta2-agonist; ICS=inhaled corticosteroid; $\mathrm{PR}=$ pulmonary rehabilitation; $\mathrm{LVR}=$ long volume reduction

provider elects to use would depend upon severity of COPD and frequency and severity of exacerbations. The COPD Flowchart can further help define those therapeutic options.

- On the CAT screen, if questions 1 and 2 (the cough/sputum questions) suggest higher symptoms, then the chronic bronchitis row is highlighted. If questions 4 or 5 (the shortness of breath questions) suggest higher symptoms and the spirometry values show moderate or severe, the emphysema row is highlighted. If the $\mathrm{mMRC}$ chart is used to trigger the interactive program, the chronic bronchitis row cannot be highlighted; if scores of 3 or 4 are chosen and spirometry values show moderate or severe, the emphysema row is highlighted. The presence of emphysema in this subset might potentially lead to evaluation for lung volume reduction surgery, or the recently FDA-approved endobronchial valve lung volume reduction.

- If spirometry results suggest moderate or severe disease (SG-2 or SG-3) the oxygen rows are highlighted, stressing that potential oxygen needs should be evaluated in these groups. While evidence continues to strongly suggest the importance of oxygen therapy in those with COPD and resting $\mathrm{O}_{2}$ saturation $<88 \%$, the recent Long-term Oxygen Treatment Trial has questioned the usefulness of oxygen in those with more mild desaturation or those with moderate desaturation only with exertion. ${ }^{21} \mathrm{~A}$ bullet point suggests that those COPD patients with hypoxemia be checked for hypercapnia potentially leading to the option of a non-invasive ventilation trial.

- The final bullet point stresses the importance of annual low-dose chest CT scanning of those patients ages 55-79 with 30 pack years and cigarette smoking in the last 15 years. While this is recommended for lung cancer screening, it is important that the scans be evaluated for other findings including emphysema, airway disease, fibrosis, and coronary calcifications to hopefully promote earlier diagnosis in these conditions as well.

- The app stresses the importance of smoking cessation, regular vaccinations, and testing for alpha-1 antitrypsin deficiency, the genetic form of COPD.

\section{View More}

COPD care requires more than just considering respiratory symptoms, lung function and exacerbations. To support that broader perspective, the "View More" section on the home screen takes the reader to a secondary menu (see Figure e 5 in the online supplement). This menu gives you another way to follow through a return visit by using the "calculator section" which calculates CAT and mMRC scores without triggering the interactive program.

Other portions of the menu support additional explorations. Anxiety and depression are extremely common in COPD and addressing these issues is a critical component of COPD care. The anxiety scorer, 
Generalized Anxiety Disorder 7 -item scale, ${ }^{22}$ and depression scorer, Patient Health Questionnaire-9 ${ }^{23}$ help define the extent of the problem and suggest therapeutic approaches. Other less commonly used but important scales include the BODE index, which provides an estimate of mortality risk beyond the very vague estimate spirometry can give. The BODE Index includes Body mass index, Obstruction gauged by $F E V_{1}$, Dyspnea gauged by $\mathrm{mMRC}$, and Exercise tolerance gauged by 6-minute walk. ${ }^{24}$ The hospitalized exacerbation scorer Dyspnoea, Eosinopenia, Consolidation, Acidemia and Atrial Fibrillation (DECAF) Score predicts mortality risk for those hospitalized with an exacerbation. ${ }^{25}$ Finally, the calculator list includes a mnemonic "HELP OUT" suggesting when consulting a pulmonologist might be considered (see Figure 8).

The RESOURCE section provides additional access to some of the components of the home screen, but in addition includes the Fletcher-Peto impact of smoking graph, ${ }^{26}$ links to the COPD Foundation website, the National Heart, Lung, and Blood Institute National Action Plan site, and provides information on how to obtain hard copies of the COPD Pocket Consultant Guide and the Foundation's COPD Action Plan.

And as a final piece of the information required during a point of care, the secondary menu provides access to the PRAXIS program (see Figure e6 in the online supplement). PRAXIS is the COPD Foundation's online hub for health care providers. In the app, the user is linked to 2 sections of PRAXIS: the PRAXIS Nexus, which is a blog of more than 80 posts, including best practices in improving care and reducing readmissions; and the Resource Repository, where the user can find 200 toolkits, videos, research article summaries and more. These cover readmissions reduction, improving education for patients, palliative care, pulmonary rehabilitation, comorbidities and many more topics. In addition, the app links to $\underline{\text { Chronic }}$ Obstructive Pulmonary Diseases: Journal of the COPD Foundation, providing continually updated lists of the most recent 25 manuscripts published by this openaccess, peer-reviewed online journal.

The COPD Foundation scientific leadership believes that the updated COPD Pocket Consultant Guide app provides a wealth of information for those caring for people with COPD. While aimed primarily at the primary care provider, the resources provided in the app should be helpful for specialists, respiratory and

\section{Figure 8. Pulmonary Referral Checklist}

\section{Pulmonary Referral Check...}

Positive responses to any of the following should lead to consideration of a pulmonary referral. Additional positive responses increase the urgency for this referral.

H Hospitalizations

$1+$ COPD hospitalizations over the last year

E Exacerbations

$2+$ exacerbations requiring steroids over the last year

L Low lung function

rapidly declining FEV1 or residual volume $>175 \%$ predicted

P Problems sleeping

Signs or symptoms of sleepdisordered breathing

O Oxygen needs

Supplemental oxygen $>2 \mathrm{~L} / \mathrm{min}$ or increasing Oxygen requirements

U Uncertain diagnosis

Inconsistent spirometry pattern or overlap syndromes with cardiovascular disease, pulmonary fibrosis or asthma

\section{T Therapy options}

Need for up-titration of therapy beyond typical inhaler regimens

$\mathrm{FEV}_{1}=$ forced expiratory volume in 1 second

physical therapists, nurses and others involved in COPD care. The Foundation will be able to monitor 
how often the app is downloaded as well as how often the individual components are used. The Foundation will work with investigators to gauge the potential impact of the app. Future versions already under discussion will likely include a patient interface as well as the present provider approach. The Foundation understands that the COPD Pocket Consultant app must evolve in order to remain relevant and useful. Input from users will be critical as we work together to improve patient care.

\section{Declaration of Interest}

Dr. Drummond reports personal fees from BoehringerIngelheim, GlaxoSmithKline, AstraZeneca, Novavax, and Mylan, outside the submitted work. Dr. Han reports personal fees from GlaxoSmithKline, Boehringer Ingelheim, and AstraZeneca and research support from Novartis and Sunovion, outside the submitted work. Dr. Kalhan reports grants from the National Heart, Lung, and Blood Institute during the conduct of the study; grants and personal fees from Boehringer Ingelheim, grants from PneumRx (BTG), grants from Spiration, grants and personal fees from AstraZeneca, personal fees from CVS Caremark, personal fees from Aptus Health, grants and personal fees from GlaxoSmithKline, personal fees from Boston Scientific, personal fees from Boston Consulting Group, outside the submitted work. Dr. Mannino reports personal fees and other from GlaxoSmithKline, outside the submitted work.
Dr. Rennard is an employee of AstraZeneca and owns shares in the organization. Dr. Sciurba reports grants from the National Institutes of Health, the Department of Defense, the Patient-Centered Outcomes Research Institute, the Commonwealth of Pennsylvania, the COPD Foundation, ResMed Corp., Forest Research Institute, PulmonX, Olympus, Gala Therapeutics, Inc., Astellas, Philips Respironics, and AstraZeneca Pharmaceuticals; grants and other from BoehringerIngelheim Pharmaceuticals, GlaxoSmithKline, and BTG International; and other from Circassia, outside the submitted work. Dr. Thomashow is co-founder and former Chair of the Board of Directors for the COPD Foundation and currently serves as its Chief Medical Officer. He has served as a consultant for Boehringer Ingelheim and served on advisory boards for GlaxoSmithKline and Astra Zeneca. Dr. Wise reports grants and personal fees from AstraZeneca /Medimmune, GlaxoSmithKline, Novartis and Boehringer-Ingelheim, personal fees from Contrafect, Pulmonx, Roche / Genentech, Spiration, Pneuma, Verona, Bonti, Denali, Aradigm, Mylan, Theravance, Propeller Health, Kiniksa, Sunovion, Merck, and Circassia; and grants from Pearl Therapeutics, outside the submitted work. Dr. Yawn reports personal fees and non-financial support from Boehringer Ingelheim and personal fees from AstraZeneca, GlaxoSmithKline, and Novartis outside the submitted work.

All other authors have nothing to declare. 


\section{References}

1. The Centers for Disease Control and Prevention (CDC). Chronic obstructive pulmonary disease (COPD) data and statistics. The CDC website. https://www.cdc.gov/copd/data.html.

Updated June 5, 2018. Accessed November 29, 2018.

2. National Center for Health Statistics. Chronic obstructive pulmonary disease (COPD) includes: chronic bronchitis and emphysema. The Centers for Disease Control and Prevention website. https://www.cdc.gov/nchs/fastats/copd.htm.

Published May 3, 2017. Accessed November 29, 2018.

3. Guarascio AJ, Ray SM, Finch CK, Self TH. The clinical and economic burden of chronic obstructive pulmonary disease in the USA. Clinicoecon Outcomes Res. 2013;5:235-245.

doi: https://doi.org/10.2147/CEOR.S34321

4. Mularski RA, Asch SM, Shrank WH, et al. The quality of obstructive lung disease care for adults in the United States as measured by adherence to recommended processes. Chest. 2006; 130(6):1844-1850.

doi: https://doi.org/10.1378/chest.130.6.1844

5. Global Initiative for Chronic Obstructive Pulmonary Disease (GOLD). Global strategy for the diagnosis, management, and prevention of chronic obstructive lung disease, 2018 report. GOLD website. https://goldcopd.org/wp-content/ uploads/2017/11/GOLD-2018-v6.0-FINAL-revised-20-Nov_ WMS.pdf Published December 2017. Accessed April 2019.

6. Rennard S, Thomashow B, Crapo J, et al. Introducing the COPD Foundation Guide for Diagnosis and Management of COPD, recommendations of the COPD Foundation. COPD. June 2013;10(3): 378-389.

doi: https://doi.org/10.3109/15412555.2013.801309

7. Yawn B, Thomashow B, Mannino DM, et al. A statement of the COPD Foundation: The 2017 update to the COPD Foundation COPD Pocket Consultant Guide. Chronic Obstr Pulm Dis. 2017;4(3):177-185.

doi: https://doi.org/10.15326/jcopdf.4.3.2017.0136

8. Qaseem A, Wilt TJ, Weinberger SE, et al. Diagnosis and management of stable chronic obstructive pulmonary disease: a clinical practice guideline update by American College of Physicians, American College of Chest Physicians, American Thoracic Society and European Respiratory Society. Ann Intern Med. 2011;155(3):179-191.

doi: https://doi.org/10.7326/0003-4819-155-3-201108020-00008

9. Wedzicha JA, Banerji D, Chapman $\mathrm{K}$ et al. Indacaterolglcopyrronium versus salmeterol-fluticasone for COPD. $N$ Eng J Med. 2016; 374:2222-2234.

doi: https://doi.org/10.1056/NEJMoa1516385
10. Papi A, Vestbo J, Fabbri L, et al. Extrafine inhaled triple therapy versus dual bronchodilator therapy in chronic obstructive pulmonary disease (TRIBUTE): a double-blind, parallel group, randomized controlled trial. Lancet. 2018; 391(10125):1076-1084. doi: https://doi.org/10.1016/S0140-6736(18)30206-X

11. Lipson DA, Barnhart F, Brealey N, et al. Once-daily single inhaler triple versus dual therapy in patients with COPD. N Engl J Med. 2018; 378(18):1671-1680.

doi: https://doi.org/10.1056/NEJMoa1713901

12. Tashkin DP, Wechsler ME. Role of eosinophils in airway inflammation of chronic obstructive pulmonary disease. Int $J$ Chronic Obstruct Pulmon Dis. 2018;13:335-349. doi: https://doi.org/10.2147/COPD.S152291

13. DiSantostefano RL, Hinds D, Le HV, Barnes NC. Relationship between blood eosinophils and clinical characteristics in a cross-sectional study of a US population-based COPD cohort. Respir Med. 2016;112:88-96. doi: https://doi.org/10.1016/j.rmed.2016.01.013

14. Magnussen H, Disse B, Rodriguez-Roisin, et al; Withdrawal of inhaled steroids and exacerbations of COPD. $N$ Engl $J$ Med. 2014;371(14):1285-1294.

doi: https://doi.org/10.1056/NEJMoa 1407154

15. Chapman KR, Hurst JR, Frent SM, et al. Long-term triple therapy de-escalation to indacaterol/glycopyrronium in patients with chronic obstructive pulmonary disease (SUNSET): A randomized, double-blind, triple-dummy clinical trial. Am J Respir Crit Care Med. 2018;198(3):329-339.

doi: https://doi.org/10.1164/rccm.201803-0405OC

16. Martinez FJ, Calverley PM, Goehring UM, Brose M, Fabbri LM, Rabe KF. Effect of roflumilast on exacerbations in patients with severe chronic obstructive lung disease uncontrolled by combination therapy (REACT): a multicenter randomized controlled trial. Lancet. 2015; 385(9971):857-66. doi: https://doi.org/10.1016/S0140-6736(14)62410-7

17. Albert RK, Connett J, Baily WC, et al. Azithromycin for prevention of exacerbations in COPD. N Engl J Med. 2011;365(8):689-698. doi: https://doi.org/10.1056/NEJMoa1104623

18. Postma D, Rabe K. The Asthma COPD Overlap Syndrome. $N$ Engl J Med. 2015;373(15): 1241-1249. doi: https://doi.org/10.1056/NEJMra1411863

19. Press VG, Arora VM, Trela KC, et al.Effectiveness of interventions to teach metered-dose and diskus inhaler techniques. A randomized trial. Ann Am Thorac Soc. 2016;13(6):816-824. doi: https://doi.org/10.1513/AnnalsATS.201509-603OC

20. Press VG, Arora VM, Shah LM, et al. Teaching the use of respiratory inhalers to hospitalized patients with asthma or COPD: a randomized trial. J Gen Intern Med. 2012; 27(10):13171325. doi: https://doi.org/10.1007/s11606-012-2090-9 
21. The long-term oxygen treatment trial research group. $A$ randomized trial of long-term oxygen for COPD with moderate desaturation. N Engl J Med. 2016; 375(17):1617-1627. doi: https://doi.org/10.1056/NEJMoa 1604344

22. Spitzer R, Kroenke K, Williams J, et al. A brief measure for assessing generalized anxiety disorder. The GAD-7. Arch Intern Med. 2006;166(10):1092-1097.

doi: https://doi.org/10.1001/archinte.166.10.1092

23. Kroenke K, Spitzer R, Williams J. The PHQ-9. Validity of a brief depression severity measure. J Gen Intern Med. 2001;16(9):606613. doi: https://doi.org/10.1046/j.1525-1497.2001.016009606.x

24. Celli BR, Cote CG, Marin JM, et al. The body-mass index, airflow obstruction, dyspnea, and exercise capacity index in chronic obstructive pulmonary disease. N Engl J Med. 2004; 350(10):1005-1012. doi: https://doi.org/10.1056/NEJMoa021322

25. Steer J, Gibson J, Bourke SC. The DECAF score: predicting hospital mortality in exacerbations of chronic obstructive pulmonary disease. Thorax. 2012;67(11):970-976. doi: https://doi.org/10.1136/thoraxjnl-2012-202103

26. Fletcher C, Peto R. The natural history of chronic airflow obstruction. Br Med J. 1977;1(6077):1645-1648.

doi: https://doi.org/10.1136/bmj.1.6077.1645 